\title{
Introduction
}

\section{Health economics and the neurosurgeon}

\author{
Nancy McLaughlin, M.D., Ph.D., F.R.C.S.C., ${ }^{1}$ \\ Alexander A. Khalessi, M.D., M.S., 2 \\ and NeIl A. Martin, M.D. ${ }^{1}$
}

\begin{abstract}
${ }^{1}$ Department of Neurosurgery, David Geffen School of Medicine, University of California, Los Angeles; and ${ }^{2}$ Department of Neurosurgery, University of California, San Diego, California
\end{abstract}

Value of care has emerged as a framework to redesign health care. In determining value, physicians will be held accountable for both clinical outcomes and cost consciousness in resource utilization; therefore, engaging physicians in the study of health economics and health care-related costs remains central in the quest for valued care delivery. The featured topic of health economics and the neurosurgeon in this issue of Neurosurgical Focus represents an effort to meet this need for the readership. Health economics, as a subdivision of economics, rigorously examines the challenges faced in promoting health for all. It encompasses the study of issues of efficiency, effectiveness, value, and behavior in the production and consumption of health and medical services.

Williams has described the scope of health economics in eight areas: 1) what, other than health care, influences health; 2) what is health and what is its value; 3 ) demand for health care; 4) supply of health care, including cost analysis; 5) microeconomic evaluation at the treatment level, including economic evaluations; 6) market equilibrium; 7) macroeconomic evaluation; and 8) planning, budgeting, and regulation mechanisms. ${ }^{1-3}$ Williams' conceptual model, known as the "plumbing diagram," demonstrates how health economics per se encompasses interrelated activities that affect every neurosurgeon's daily practice. It stresses how multiple professionalshealth economists, epidemiologists, statisticians, physicians, administrators, politicians, and so forth-are essential to the development of this field of knowledge.

Our call for papers was therefore very broad, aiming

Please include this information when citing this paper: DOI: 10.3171/2014.9.FOCUS14643. to encourage our scientific community to share their best work in all areas of health economics. Authors of submitted manuscripts merit commendation for their work: over 45 manuscripts were reviewed. The papers published in this edition represent the best examples of various types of economic assessments, offering different perspectives and using varied data sources. A multidisciplinary team reviewed all manuscripts to ensure the methodology section was comprehensive and detailed; thus, readers of Neurosurgical Focus will be able to use this edition as a reference for future endeavors. Authors were also encouraged to provide a detailed limitation section to provide critical context and nuance that may impact observations.

The first few articles feature an overview on health care economics in general as well as costing methodology, providing readers with the knowledge and tools required to appraise published economic evaluations and to direct high-quality health care economics assessments (McLaughlin, Ong et al.). They also introduce the readers to a costing model that has gained worldwide popularity in health economics: time-driven activity-based costing (TDABC; McLaughlin, Burke et al.). This model estimates the cost of each resource used for treating a patient's medical condition and combines it with the quantity of time each resource is used for each activity during a patient's care. McLaughlin and colleagues describe their implementation process, as well as lessons learned across the care continuum, and report how TDABC has actively engaged health care providers in costing activities and care redesign within their institutions.

Subsequent articles discuss economic evaluations and cost analysis and contain examples applied throughout various neurosurgical subspecialties. All authors have taken their economic assessments one step further by providing one or many of the following: 1) cost trends regarding year of treatment, geographic location of the hospital, hospital characteristics, and so forth (articles by Menger et al., Lam et al., Little et al., and Sheen James et al.); 2) drivers of increased cost or resource utilization (Little et al.; Lam et al.; and McLaughlin, Martin et al.); 3) integration of cost analysis data in decision making (Menger et al. and Mansfield et al.); 4) integration of modeling and development of cost models (Lam et al. and Zygourakis et al.); and 5) 
development of tools to identify high-impact cost activities (McLaughlin, Martin et al.).

In their article on the cost of academic practice, Lieber and colleagues assessed the desire of interviewees to mitigate interview costs through ideas such as sharing hotel rooms and transportation, willingness to stay with local students, and coordinating interview schedules. These authors provide an eye-opening perspective on the opportunities we have, as a scientific community, to contain the cost of our academic activities and to teach this valuable lesson to the future generation.

The final article in this issue by Rosenow and Orrico assesses neurosurgeons' response to cutbacks in the Medicare program beyond just their participation status. The authors' survey sheds light on growing barriers to care access for Medicare patients that will increase as reimbursement declines.

Taken together, these papers introduce essential ele- ments of health economics to the Focus readership. Beyond their academic value, the papers offer larger signposts for the advancement of neurosurgical care in a challenging health care environment.

(http://thejns.org/doi/abs/10.3171/2014.9.FOCUS14643)

\section{Disclosure}

The authors report no conflict of interest.

\section{References}

1. Glied S, Smith PC (eds): The Oxford Handbook of Health Economics. Oxford: Oxford University Press, 2011

2. Graves N, Halton K, Jarvis W: Economics and Preventing Healthcare Acquired Infection. New York: Springer, 2009

3. Williams AH: Health economics: the cheerful face of the dismal science?, in Health and Economics: Proceedings of Section F (Economics) of the British Association for the Advancement of Science, Bristol. London: Macmillan, 1987, pp 1-11 